\title{
Reducing inflammation in COPD: the evidence builds
}

\section{Neil Barnes}

\section{Anti-inflammatory activity of a combination of an inhaled steroid and a long-acting $\beta_{2}$ agonist in COPD}

t has been accepted for more than 20 years that asthma is an inflammatory disease of the airways, but it is more recent that airways inflammation has been accepted to be important in chronic obstructive pulmonary disease (COPD). ${ }^{1}$

Airways inflammation is found in heavy smokers who have not developed airflow obstruction and is qualitatively similar to that seen in smoking-related COPD. ${ }^{23}$ Some, but not all, studies have shown a relationship between the severity of airflow obstruction and the degree of inflammation, lending support to the hypothesis that airway inflammation is important in COPD. ${ }^{4}$ The airway inflammation is characterised by an increase in CD8+ $\mathrm{T}$ cells and macrophages in the airway wall. Increased numbers of neutrophils are seen in the airway wall, particularly in more severe disease, but neutrophils are particularly prominent in sputum. ${ }^{267} \mathrm{~B}$ cells are increased in more severe disease and there are increased numbers of mast cells. ${ }^{2}$ The main site of airflow obstruction in COPD is considered to be in the small airways which are inaccessible to normal bronchoscopic biopsy techniques; however, the pattern of airway inflammation seen in the large airways accessible to a bronchoscope and in the smaller airways is essentially similar. ${ }^{2}$ Although airway inflammation is found in COPD, knowing which are the most important cells, cytokines and mediators is fraught with difficulty. Ultimately, understanding which of the pathways are important will depend on intervention studies which attempt to associate changes in inflammation with clinical benefit.

There are many intervention studies in asthma, investigating the effect of antiinflammatory treatment on airway inflammation in chronic asthma or following allergen challenge. However, there are very few studies in COPD and the study by Bourbeau et al published in this issue in Thorax is therefore of value (see page 938)..$^{8-12}$ Previous studies by our group and others have shown in double blind, placebo controlled studies that inhaled corticosteroids given alone for 3 months have only a minor effect on airway inflammation with a reduction only in the number of mast cells..$^{8-10}$ Well constructed studies of the effect of inhaled or oral steroids on measures of inflammation in sputum have generally shown no effect on neutrophils. ${ }^{67}$ A large study reported by our group comparing combination therapy with fluticasone/ salmeterol over a 3-month period with placebo showed reductions in a wide range of inflammatory cells, particularly $\mathrm{CD} 8+\mathrm{T}$ cells and CD4+ $\mathrm{T}$ cells in biopsy specimens and a reduction in the percentage of neutrophils in sputum. ${ }^{11}$ Although this study had the strength of being large with a statistical power to show changes in the three primary outcome variables, it had the disadvantage of only comparing combination therapy with placebo. Bourbeau et al have compared placebo, fluticasone $500 \mu \mathrm{g}$ twice daily and a combination of fluticasone $500 \mu \mathrm{g}$ twice daily and salmeterol $50 \mu \mathrm{g}$ twice daily in well characterised patients with COPD. The inclusion of the inhaled steroid alone adds considerable support to the previous observations. They found a significant reduction in CD8+ T cells in the combination treated group with no change in the group treated with fluticasone alone. They also found a significant reduction in macrophages (CD68+) but no change in neutrophils or eosinophils in biopsy specimens. The reduction in macrophages is different from the finding in our study where, for reasons that are unclear, the number of macrophages in both the placebo and active treatment groups rose over the 3 months of the study with no difference between the groups. In our study the percentage of neutrophils was reduced in sputum, but we have not yet reported data on neutrophil numbers in biopsy specimens. Previous studies, both in asthma and COPD, have shown that measurements of inflammation in the airway wall made from biopsy specimens and in the airway lumen either by sputum or bronchoalveolar lavage do not necessarily give the same picture of anti-inflammatory changes. Bourbeau et al do not report measuring increased sputum inflammation. ${ }^{12}$ The percentage reductions in cell counts in their study and in our study are of the order of $40 \%$, which are likely to be of biological significance.

If airways inflammation is important in COPD, what might be the clinical effects produced by a reduction in inflammation? Given the severity of the structural changes that occur in the airways of patients with COPD, it is a little unlikely that any marked improvement in airflow obstruction would occur, at least in the short term. It is more likely that a reduction in inflammation might decrease the chance of having an exacerbation of COPD, reduce mortality or reduce the rate of decline in forced expiratory volume in $1 \mathrm{~s}\left(\mathrm{FEV}_{1}\right)$. It is tempting to speculate that the reduction in exacerbations of COPD, which have been shown with the combination of inhaled steroids and long-acting $\beta_{2}$ agonists, may be related to reductions in inflammation. ${ }^{13-16}$ The reduction in rate of decline of $\mathrm{FEV}_{1}$ and the possible reduction in mortality seen in the TORCH study may also be related to reduced inflammation. ${ }^{16}$

The results of studies of the effect of pharmacotherapy on inflammation in COPD have a broader significance. They show that, in relatively low numbers of subjects in studies over a 3-month period, treatments can have a significant antiinflammatory effect. As new anti-inflammatory drugs become available to be investigated in COPD, these types of studies may be important at an early stage to demonstrate anti-inflammatory action, as studies in which the end point is the rate of decline in $\mathrm{FEV}_{1}$ or a reduction in exacerbations would require much longer studies in much larger numbers of subjects. The fact that a combination of an inhaled steroid and a long-acting $\beta_{2}$ agonist can significantly reduce inflammation in COPD does indicate that this inflammation is tractable to pharmacological intervention which, again, should encourage those who are developing novel anti-inflammatory treatments for COPD to continue to pursue this aim. ${ }^{17} \mathrm{~A}$ criticism which is frequently levelled at these studies is that they are only looking at the large airways when the important site of inflammation may be the small airway but, until techniques which can safely and reliably sample small airways are developed, studies looking at airway inflammation by bronchial biopsies combined with induced sputum or bronchoalveolar lavage to sample the lumen of the airways will remain an invaluable way of understanding the information of airway inflammation in COPD. 
Thorax 2007;62:927-928.

doi: 10.1136/thx.2007.082677

Correspondence to: Professor Neil Barnes, Department of Respiratory Medicine, The London Chest Hospital, Bonner Road, London E2 9JX,

UK; neil.barnes@bartsandthelondon.nhs.uk

\section{REFERENCES}

1 Global Initiative for Chronic Obstructive Lung Disease. Global strategy for the diagnosis, management and prevention of chronic obstructive lung disease. Bethesda: National Heart Lung and Blood Institute, 2006.

2 Hogg JC, Chu F, Utokaparch S, et al. The nature of small-airways obstruction in chronic obstructive pulmonary disease. N Engl J Med 2004;350:2645-53.

3 O'Shaughnessy T, Ansari TW, Barnes NC, et al. Inflammation in bronchial biopsies of subjects with chronic bronchitits: inverse relationship of CD8+ T lymphocytes with $\mathrm{FEV}_{1}$. Am J Respir Crit Care Med 1997; 155:852-7.

4 Saetta M, Baraldo S, Corbino L, et al. CD8+ve cells in the lungs of smokers with chronic obstructive pulmonary disease. Am J Respir Crit Care Med 1999; 160:711-7.
5 Stanescu D, Sanna A, Veriter C, et al. Airways obstruction, chronic expectoration, and rapid decline of $F E V_{1}$ in smokers are associated with increased levels of sputum neutrophils. Thorax 1996:51:267-71.

6 Keatings VM, Barnes PJ. Granulocyte activation markers in induced sputum: comparison between chronic obstructive pulmonary disease, asthma and normal subjects. Am J Respir Crit Care Med 1997; 155:449-53.

7 Keatings VS, Jatakanon A, Wordsdell YM, et al Effects of inhaled and oral glucorticosteroids on inflammatory indices in asthma and COPD. Am J Respir Crit Care Med 1997;155:542-8.

8 Hattotuwa KL, Gizycki MJ, Ansari TW, et al. The effects of inhaled fluticasone on airway inflammation in chronic obstructive pulmonary disease: a double-blind placebo-controlled biopsy study. Am J Respir Crit Care Med 2002; 165:1592-6.

9 Gizycki MJ, Hattotuwa KL, Barnes N, et al. Effects of fluticasone propionate on inflammatory cells in COPD: an ultrastructural examination of endobronchial biopsy tissue. Thorax 2002;57:799-803.

10 Verhoeven GT, Hegmans JP, Mulder PG, et al. Effects of fluticasone propionate in COPD patients with bronchial hyperresponsiveness. Thorax 2002;57:694-700.
11 Barnes NC, Qiu Y-S, Pavord ID, et al. Antiinflammatory effects of salmeterol/fluticasone propionate in chronic obstructive lung disease. Am J Respir Crit Care Med 2006;173:736-43.

12 Bourbeau J, Christodoulopoulos P, Maltais F, et al. Effect of salmeterol/fluticasone propionate on airway inflammation in COPD: a randomised controlled trial. Thorax 2007;62:938-43.

13 Calverley P, Pauwels R, Vestbo J, et al. Combining salmeterol and fluticasone in the treatment of chronic obstructive pulmonary disease. Lancet 2003;361:1449-56.

14 Mahlet DA, Wire P, Horstman D, et al. Effectiveness of fluticasone propionate and salmeterol combination delivered via the Diskus device in the treatment of chronic obstructive pulmonary disease. Am J Respir Crit Care Med 2002;166:1084-91.

15 Szafranski W, Cukier A, Ramirez R, et al. Efficacy and safety of budesonide/formoterol in the management of chronic obstructive pulmonary disease. Eur Respir J 2003;21:74-81.

16 Calverley PMA, Anderson JA, Celli B, for the TORCH investigators, et al. Salmeterol and fluticasone propionate and survival in chronic obstructive pulmonary disease. N Engl J Med 2007;356:775-89.

17 Gamble E, Grootendorst D, Brightling E, et al. Antiinflammatory effects of the phosphodiesterase 4 inhibitor cilomilast (Ariflo) in chronic obstructive pulmonary disease. Am J Respir Crit Care Med 2003; 168:976-82.

\section{Investigating outbreaks}

\section{A J Newman Taylor}

\section{Precise identification of the specific cause of the disease is not necessarily essential to initiate effective control measures}

\section{n 1854, John Snow wrote on the outbreak of cholera in London: ${ }^{1}$ \\ "the most terrible outbreak of cholera which ever occurred in this kingdom is probably that which took place in Broad Street, Golden Square and the adjoining streets, a few weeks ago. Within two hundred and fifty yards of the spot where Cambridge Street joins Broad Street, there were upwards of five hundred fatal attacks of cholera in ten days".}

An outbreak is usually thought of as a sudden localised increase in disease incidence. Classically, outbreaks are the outcome of infection but, increasingly, noninfectious agents are identified as their causes. These may be newly introduced without recognition of the associated risk or a well recognised risk to which the level of exposure is not appreciated. Several examples have been reported in recent years: an outbreak of obliterative bronchiolitis in the workforce of a microwave popcorn factory in USA probably caused by diacetyl, a volatile agent for flavouring butter; ${ }^{2}$ outbreaks of organising pneumonia in Spain and in North Africa in textile spray workers which, in both instances, followed the introduction of a textile dye whose chemical formulation had been changed; ${ }^{3}$ and outbreaks of lymphocytic bronchiolitis and peribronchiolitis in workers in nylon flock production in the USA. ${ }^{4}$ In each of these cases the outbreak followed the introduction of a new chemical or process into industry. In contrast, an outbreak of asthma in a detergent manufacturing plant in UK in the late 1990s caused by allergy to enzymes was a recurrence of a problem well recognised in the late 1960s. ${ }^{5}$ The risk of occupational asthma caused by the inhalation of powdered enzymes used in detergent manufacture had been considered a problem solved for 25 years by encapsulation of the powdered enzymes into granules, a formulation introduced in the 1970s and which had been invariably used in this factory. However, the process used in the factory to add the enzymes to detergent probably led to the break up of the granules into powder, recreating the circumstances of exposure of the late 1960s.

Outbreaks can be considered as failures of control; they are important to recognise, to investigate and their cause identified as the basis for remedial action. Identification of the cause of an outbreak of disease in a workforce is informed by knowledge of the classical epidemiological descriptors of time, place and person. What was the time course of the outbreak-did it follow the introduction of a new material or change in process? Was the disease more frequent in one part of the factory or in those working in a particular process? How did those who developed the disease differ from those who did not?

In this issue of Thorax Robertson and colleagues describe their investigation of an outbreak of allergic alveolitis (hypersensitivity pneumonitis) and occupational asthma in a car manufacturing plant in the UK (see page 981). ${ }^{6}$ While allergic alveolitis and asthma have previously been described in these workforces in the USA, ${ }^{7-9}$ this outbreak is the first reported in the UK and was larger, particularly in the number of cases of asthma reported. In one similar outbreak of allergic alveolitis in a car manufacturing plant in the USA, six cases of allergic alveolitis all worked in a machining area of the factory where they used a synthetic metal working fluid (MWF) which had been introduced 6-8 months earlier. All six cases, but not eight of nine workforce controls, had precipitating antibodies in their serum to Pseudomonas fluorescans which had been cultured from used MWF.? 